\title{
Montaj Hattı Dengelemede Çevrim Süresinin Minimizasyonu için Yeniden İşleme İstasyonunun Kullanımı: Hata Oranı ve İstasyon Pozisyonunun Etkileri
}

\author{
Using Rework Station for Minimizing Cycle Time in Assembly Line Balancing: \\ Effects of Rework Rate and Station Position
}

\author{
Elif KAYMAZ $^{1}$ (D) , Fatih ÇAVDUR ${ }^{1}$ (i) \\ ${ }^{1}$ Uludağ Üniversitesi, Mühendislik Fakültesi, Endüstri Mühendisliği Bölümü, Bursa, Türkiye
}

Öz

Montaj hatlarında yeniden işleme istasyonları genellikle yalnızca uygun olmayan ürünlerin yeniden işlenmesi için kullanılmaktadır. Bununla birlikte, yeniden işleme istasyonunun yalnızca bu amaçla kullanılması, özellikle montaj hattında hata oranının düşük olması durumunda, istasyonda bulunan kaynakların kullanım oranını düşürmektedir. Bu çalışmada, yeniden işleme istasyonunun standart bir iş istasyonu olarak kullanılmasını dikkate alarak çevrim süresini minimize etmeyi amaçlayan bir karışık-tamsayılı programlama modeli önerilmektedir. Önerilen model, montaj hattındaki farklı hata oranlarının yanısıra, yeniden işleme istasyonunun sadece montaj hattı sonunda değil, farklı pozisyonlarda konumlandırılmasını da dikkate almaktadır. Modelin performansı, literatürdeki çeşitli örneklemler üzerinde test edilmiştir.

Anahtar Kelimeler: Montaj Hattı Dengeleme, Yeniden İşleme İstasyonu, Tamsayılı Programlama, Çevrim Süresi Minimizasyonu

\begin{abstract}
This paper includes five sections as (i) Introduction, (ii) Literature Review, (iii) Material and Method, (iv) Findings and (v) Discussion and Conclusion. In the first section (Introduction), a brief introduction to assembly lines and assembly line balancing is presented and the outline of the paper is summarized. The second section (Literature Review) presents some related studies from the literature. Material and Method section makes the problem definition and describes the proposed mixed-integer programming model. Following section (Findings) presents the implementation results where some example problems from the literature are solved using the proposed mixed-integer programming model. In the last section (Discussion and Conclusion), concluding remarks are presented.

In assembly lines, rework stations are generally used only for reprocessing of defective products. However, the use of the rework station only for such reprocessing operations reduces the utilizations of the resources available in the station, especially if the defect rate of the assembly line is low. It is noted that the idea of using rework stations for performing standard tasks gets attention in such assembly lines with relatively low defect rates to minimize cycle times and use available resources more efficiently. In this paper, we propose a mixed-integer programming model to minimize the cycle time of an assembly line where the rework station is also used for performing standard tasks in addition to reprocessing operations of defective products. Using the proposed model, we take into account different rework station positions rather than just positioning the rework station at the end of the assembly line as well as different defect rates. Additionally, it is also possible to penalize the rework station standard task assignments with the proposed mixed-integer programming model using a model parameter to restrict the number of the standard tasks assigned to the rework station.

A numerical example is presented for illustration using a sample dataset (Jackson dataset) from the literature with 11 tasks and 3 stations. Consideration of the rework station for performing standard tasks then increases the total number of stations to four (i.e., 3 standard stations +1 rework station) in the numerical example. We present the solution details for the numerical example by representing all task assignments to the standard stations as well as the rework station. We also consider different rework station positions and rework rates as well as two cases where it is allowed to assign standard tasks to the rework station without any restriction and it is penalized (restricted) to make such assignments,
\end{abstract}


respectively, using the corresponding model parameter. For the convenience of the reader, original problem solution is also provided.

In addition to the Jackson dataset, we also test the performance of the proposed mixed-integer programming model using two other sample datasets (Mitchells and Heskiaoff datasets) with 21 and 28 tasks, respectively, accessible at "http://assembly-line-balancing.mansci.de". In computational experiments, all problems are solved to optimality for two different number-of-stations combinations ( 3 and 4 stations for the Jackson dataset, 3 and 5 stations for the Mitchells dataset and 4 and 5 for the Heskiaoff dataset) with three different rework station positions (as the last three station positions for the corresponding dataset) and rework rates (rework rates of $0 \%, 25 \%$ and $50 \%$ ) are considered. Maximal Software Mathematical Programming Language (MPL) with Gurobi Optimizer is used for performing the computational experiments. We present the results (i.e., cycle time and computer solution time) for each dataset with a particular number of stations and its modified version with an additional station (i.e., rework station) in the corresponding datasets. We analyze the effects of different rework station positions and defect rates on the solutions. It is noted that the datasets considered in this study are solved to optimality in reasonable time periods since the maximum of computer solution times is 0.04 seconds observed for the Heskiaoff dataset as the largest dataset considered in this study. It is also noted that the proposed mixed-integer programming model can be used for assigning standard tasks to the rework station of an assembly line if it is extended to consider additional constraints about some practical issues in real-life problems such as human factors (ergonomics) or technical restrictions. On the other hand, recent technological developments (i.e., smart factories etc.) might make it easier to deal with such issues in real-life assembly lines of the near future. In future studies, the proposed mixed-integer programming model can be extended to include such real-life characteristics. Additionally, although the optimal solutions of the assembly line balancing problems of the sample datasets considered in this study can be obtained in reasonable time periods using a personal computer, considering larger problem instances might require more computational power or the development of some heuristics or meta-heuristics.

Keywords: Assembly Line Balancing, Rework Station, Integer Programming, Cycle Time Minimization

\section{GíRiş}

Çeşitli amaçlara göre (çevrim süresinin, istasyon sayıs1nın minimizasyonu vb.) montaj hatlarında gerçekleştirilen hat dengeleme çalışmaları genel olarak Montaj Hattı Dengeleme (MHD) ve bu çalışmalara karşlık gelen problemler de MHD problemleri olarak adlandırılmaktadır.

Montaj hatlarında ardışık iş istasyonlarında sırasıyla işlem gören iş parçası son istasyondan nihai ürün olarak çıkmaktadır. Genel olarak, son istasyonda gerçekleştirilmesi gereken görevler tamamlandıktan sonra, ayrıca ürün ile ilgili gerekli görülen kalite kontrol işlemleri de yapılmaktadır. Söz konusu kalite kontrol işlemleri sonucunda, ürün önceden belirlenen özellikleri taşımıyor ise (ürün hatalı ise) bazen hatanın meydana geldiği iş istasyonuna, bazen de montaj hattından bağımsız olarak çalışan bir Yeniden İşleme (YI) istasyonuna gönderilerek, gerekli hata giderme çalışmaları gerçekleştirilmektedir [1]. Yİ istasyonunun yalnızca hatalı ürünlerin hata giderme işlemleri için kullanılması, özellikle montaj hattındaki hata oranının düşük olması durumunda, bu istasyonda bulunan iş gücü, makine-teçhizat vb. kaynakların etkin bir biçimde kullanılamamasına neden olmaktadır. Bu çalışmada, yeniden işleme istasyonunun standart bir iş istasyonu olarak kullanılmasını dikkate alarak çevrim süresini minimize etmeyi amaçlayan bir karışık-tamsayllı programlama modeli önerilmektedir.

Yİ istasyonu genellikle montaj hattının sonuna konumlandırılmakla birlikte, bu çalışmada ele alındığı şekilde standart bir iş istasyonu olarak kullanılması durumunda, Yİ istasyonuna atanacak görev sayısı öncelik ilişkileri nedeniyle istasyon pozisyonuna bağlı olarak değişkenlik gösterebileceğinden, Yİ istasyonunun hangi pozisyonda konumlandırıldığı da önem kazanmaktadır. Bu çalışmada, Yİ istasyonunun son üç istasyon pozisyonunda konumlandırılması ele alınarak çözüme olan etkileri incelenmiştir. Buna ek olarak, öncelikli olarak hata giderme işlemleri için tasarlanmış olan Yİ istasyonuna atanabilecek olan görevlerin sayısı, montaj hattı hata oranına bağlı olarak da değişkenlik göstereceğinden, üç farklı hata oranı için elde edilen çözümler analiz edilmiştir.

\section{LITERATÜR INCELEMESi}

Literatürde montaj hatlarının dengelenmesi kavramı ilk kez 1954 yılında Bryton tarafından dikkate alınmıştır [2]. Montaj hattı dengeleme probleminin tanımını ise Salveson 1955 yılında yapmıştır [3]. MHD problemlerinin sınıflandırılması ile ilgili çeşitli kaynaklarda farklı sınıflandırmalara rastlamak mümkündür. Örneğin, Ghosh ve Gagnon [4] tarafindan yapılan bir çalışmada MHD problemleri Şekil 1'deki gibi sınıflandırılmıştır.

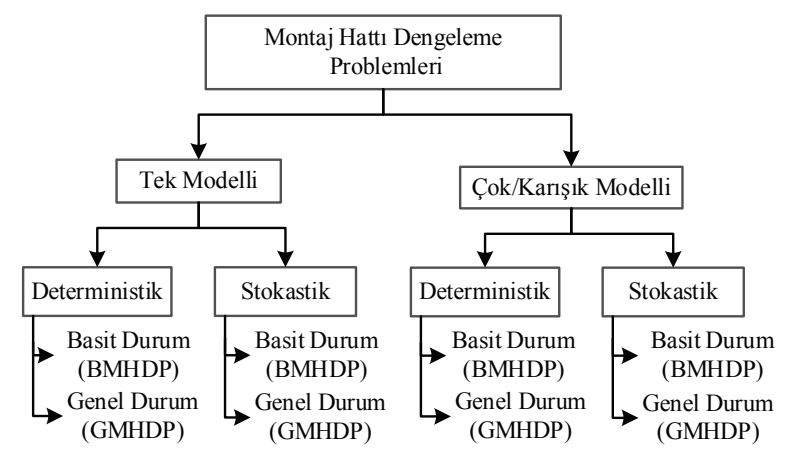

Şekil I. MHD problemlerinin sınıflandırılması [4] 
$\mathrm{Bu}$ sınıflandırmaya göre MHD problemleri tek modelli ve çok/karışık modelli olmak üzere iki sınıftan oluşmaktadır. Tek modelli montaj hatlarında tek tip ürün modeli üretilirken çok/karışı modelli montaj hatlarında birden fazla tipte ürün üretilmesi söz konusudur. Öte yandan, görev sürelerine bağlı olarak da deterministik ve stokastik görev süreli montaj hatları olmak üzere iki sınıfa ayrılmaktadır. Bu s1nıflandırmanın ötesinde, MHD problemindeki en temel unsurların dikkate alındığı montaj hattı dengeleme problemleri Basit Montaj Hattı Dengeleme Problemleri (BMHDP) olarak adlandırılmaktadır. BMHDP için çeşitli varsayımlar kullanılmaktadır [5].

- Tüm girdi parametreleri belirlidir.

- Bir görev birden fazla istasyona bölünemez.

- Teknolojik ve organizasyonel kisıtlardan dolayı görevler keyfi bir sırayla gerçekleştirilemez.

- Tüm görevler yapılmalıdır.

- Tüm istasyonlar tüm görevleri gerçekleştirebilecek ekipman ve donanıma sahiptir.

- Her görev herhangi bir istasyonda yapılabilir.

- Tüm hat, besleyici veya paralel alt montaj hatlı olmayacak şekilde seri olarak düzenlenmiş olmalıdır.

- Çevrim süresi verilmiştir ve sabittir (BMHDP-1 için).

- İstasyon sayısı verilmiştir ve sabittir (BMHDP-2 için).

BMHDP ile ilgili belirlenmiş olan varsayımlar gerçek dünya montaj hattı sistemlerine göre oldukça kısıtlayıcı olmaktadır. Bu nedenle, son zamanlarda alan kısitları, bölgesel kısıtlar, paralel istasyon ve paralel görev gibi çeşitli ek kısıtlar ve problem özellikleri içeren daha genelleştirilmiş montaj hattı dengeleme problemlerini (GMHDP) tanımlama, formüle etme ve çözme yönündeki çalışmalar artmıştır [6]. BMHDP ve GMHDP ile ilgili olarak kapsamlı çalışmalar arasında Scholl ve Becker [7], Becker ve Scholl [6] tarafından gerçekleştirilen çalışmalar sayılabilir.

BMHDP amaç fonksiyonuna bağlı olarak çeşitli sınıflara ayrılmaktadır. Bunlar BMHDP-1, BMHDP-2, BMHDP-E ve BMHDP-F'dir. BMHDP-1 (Tip-1 MHD problemi) ve BMHDP-2 (Tip-2 MHD problemi) ikili bir ilişkiye sahiptir; BMHDP-1 verilen sabit çevrim süresi için istasyon say1sını minimize ederken, diğeri ise verilen sabit istasyon sayısı için çevrim süresini minimize etmektedir. BMHDP-1 araştırmacılar için popüler bir araştırma alanı olmasına rağmen, BMHDP-2 daha az çalışılmıştır [8]. BMHDP-E, hat etkinliği maksimize etmeye ve boşta kalma süresini minimize etmeye, başka bir ifadeyle, iş istasyonlarının sayısını ve çevrim süresini minimize etmeye çalışmaktadır [9]. BMHDP-F istasyon sayısı ve çevrim süresinin belirli bir kombinasyonu için uygun bir hat dengesi sağlamayı amaçlamaktadır [7]. Bu çalışmada dikkate alınan problem Tip 2 MHD problemi sinıfina girmektedir.

MHD problemleri ile ilgili bir diğer sınıflandırmada Şekil 2'de verilmiştir [10]. Bu sınıflandırmaya göre, MHD problemleri, tek-çok/karışık modelli ve deterministik-stokastik görev süreli MHD problemleri olmak üzere iki ayrı sınıftan oluşmaktadır. Önceki sınıflandırmadan farklı olarak bu sınıflandırmada, montaj hatları hattın yerleşimine göre düz ve U tip hatlar olarak iki sinıfta incelenmektedir. Düz montaj hatları birbiri ardına dizilmiş iş istasyonlarından oluşmaktadır [11]. Bu tip montaj hatları iş akışının daha hızlı olması, konveyör sistemlerinin daha kolay uygulanabilirliği açısından sıklıkla tercih edilmektedir. U tipi montaj hatlarında hem giriş hem de çıkış aynı konumdadır. Bu hatlarda iki kaynağın arasına yerleştirilen iş̧̧ilerin birinden diğerine yürümesine izin verilmektedir. Bu nedenle aynı çevrim süresince burada çalışan işçiler iki veya daha fazla iş parçası üzerinde çalışabilirler. Son yıllarda, tam zamanında üretim sistemlerinin bir sonucu olarak U-tipi hatlar daha yaygın biçimde kullanılmaya başlanmıştır [11]. Yapılan sınıflandırmalarda genellikle düz hatlar ve U tipi hatlar kullanılsa da bu tip hatların yanısıra montaj hatlarında paralel hatlar [12] ve çift yönlü hatlar [13] olmak üzere çeşitli hat yapıları da kullanılmaktadır.

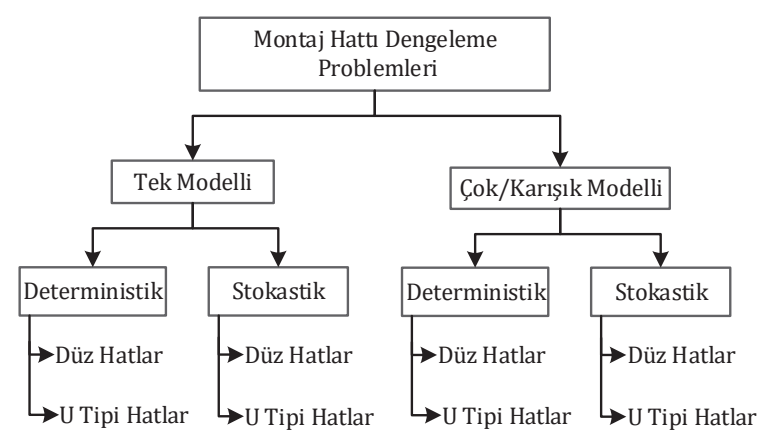

Şekil 2. MHD problemlerinin sinıflandırılması [10]

MHD problemlerinin çözüm yöntemleri, kesin çözüm ve yaklaşık çözüm veren yöntemler olmak üzere sınıflandırılabilir. Kesin çözüm veren yöntemler tamsayılı programlama [14] dal sinır algoritması [15], dinamik programlama [16] ve hedef programlama [17] gibi yöntemlerden oluşmaktadır. Yaklaşık çözüm veren yöntemler kesin çözüm veren yöntemlerin aksine optimalliği garanti etmemekle birlikte, daha kısa sürede iyi çözümler sunabilmeleri nedeniyle tercih edilebilmektedir. Yaklaşık çözüm veren yöntemler sezgisel ve meta-sezgisel yaklaşımları içerir. Sezgisel yaklaşımlar 
belirli bir problemin çözümünde kullanılırlar. Diğer yandan, çok sayıda çeşitli meta-sezgisel yaklaşımlar çok farklı tipte optimizasyon problemleri için kullanılmaktadır [18]. MHD problemlerinin çözümünde kullanılan kesin çözüm ve yaklaşık çözüm veren yöntemlerin kapsamlı bir incelemesi Boysen ve ark. [19] tarafından verilmiştir.

$\mathrm{Bu}$ çalışmada ele alınan tek modelli deterministik BMHDP'nin çözümü için literatürde çok sayıda yaklaşım önerilmiştir. Deckro ve Rangachari [20] çalışmalarında istasyon sayısını minimize etmek amaciyla bir hedef programlama modeli geliştirmişlerdir. Kilincci ve Bayhan [21] tarafindan yapılan çalışmada BMHDP-1 problemi ele alınmış, belirli bir çevrim süresi için istasyon sayısını minimize etmek amaçlanmıştır. Yapılan çalışmada etkinleştirilmiş aramalar için bir Petri net yaklaşımı önerilmiştir. Rubinovitz ve Levitin [22] deterministik görev süreli tek modelli MHD problemi için bir genetik algoritma geliştirmişlerdir. Kim ve ark. [23], BMHDP'nin çözümü için çeşitli amaçların dikkate alındığı bir genetik algoritma geliştirmişlerdir. Suwannarongsri ve Puangdownreong [24] tarafindan gerçekleştirilen çalışmada, tek modelli MHD problemi için tabu arama ve kısmi rastgele permütasyon tekniği kullanılarak yeni bir hibrit yöntem geliştirilmiştir. Tapkan ve ark. [25] tarafından gerçekleştirilen çalışmada ise istasyon sayısını minimize etmek amacıyla bir tamsayılı programlama modeli formüle edilmiş, ancak problemin karmaşıklığından dolayı arı algoritması ve yapay arı kolonisi algoritması önerilmiştir. Baykasoglu ve Dereli [26], deterministik görev süreli çift taraflı MHD probleminin çözümü için karınca kolonisi tabanlı bir algoritma geliştirmişlerdir. Baykasoğlu [27] tarafindan yapılan bir diğer çalışmada ise, basit ve U-tipi MHD problemleri için "düzgünlük indeksi" ve "hat performansını" maksimize etmek (veya istasyon sayısını minimize etmek) amaçlanmış, bu amaç doğrultusunda tavlama benzetimi tabanlı bir algoritma geliştirilmiştir.

Bir montaj hattının yalnızca görev sürelerini dikkate alarak dengelenmesi, bazı operatörlerin fiziksel olarak aşırı iş yüküne maruz kalmasına neden olabilir [28]. Ergonomi ve iş sağlığ 1 alanında yapılan çalışmalar aşırı iş yükünün işle ilgili yaralanmaların ana nedenlerinden biri olduğunu göstermiş̧ir. Ergonomik anlamda iyi tasarlanmamış montaj hatları, çalışanlar üzerinde kalııı hasarlara neden olabilmektedir. Bu nedenle hat dengeleme çalışmaları yapılırken ergonomik risk faktörlerinin de dikkate alınması oldukça önemlidir [29].

MHD problemlerinde ergonomik faktörlerin dikkate alındığı çalışmalar oldukça sınırlıdır. Güner ve Hasgül [30] tarafından yapılan çalışmada ergonomik faktörler içeren yeni bir tam sayılı programlama modeli önerilmiştir.
Barathwaj ve ark. [31] çalışmalarında istasyon sayısı ve her istasyondaki gerçekleştirilen iş yükü içeriğini azaltmayı amaçlamaktadırlar.

Bu çalışmada, Yİ istasyonunun standart bir iş istasyonu olarak kullanılmasını dikkate alarak çevrim süresini minimize etmeyi amaçlayan bir karışı-tamsayılı programlama modeli önerilmektedir. Önerilen model ile görevler arasındaki öncelik ilişkilerine bağlı olarak Yİ istasyonunun farklı pozisyonlarda konumlandırılmasının ve montaj hattındaki hata oranının çözüme olan etkileri incelenmiştir. Buna ek olarak, Yİ istasyonuna atanabilecek işlerin sayısını sınırlandırmak için kullanılan ceza katsayısı ile bu istasyonunda çalışan kişilerin maruz kalabileceği ergonomik risk unsurlarının (Yİ istasyonunda standart olmayan işlerin yapılması nedeniyle daha fazla yorulma vb.) da model dâhil edilmesi sağlanmaya çalışılmıştır.

\section{MATERYAL VE METOT}

Bu çalışmada deterministik görev süreli tek modelli düz montaj hattı ile ilgili hat dengeleme problemi ele alınmıştır. Seri üretim montaj hatlarında farklı işlem sürelerine sahip operasyonlar bir araya gelerek istasyonları oluşturmakta ve istasyonlarda belirlenen sıraya göre işlem gören iş parçaları son istasyondan ürün olarak çıkmaktadır. Son istasyondan çıkan ürün belirlenen tanımlara uygun değil ise başka bir ifadeyle hatalı ürün ise Yeniden İşleme (Yİ) istasyonuna gönderilerek bu istasyonda gerekli olan denetleyici ve düzenleyici işlemler gerçekleştirilir.

Yİ istasyonunun çalışması montaj hattındaki hata oranına göre değişkenlik göstermektedir. Hata oranı düşük olduğu durumda bu istasyonda bulunan kaynaklar daha az kullanılmaktadır bu durumda burada bulunan kaynakların verimli şekilde kullanılmamasına neden olmaktadır. Çalışmada üç farklı hata oranı dikkate alınmıştır.

Montaj hattındaki öncelik ilişkileri görevlerin yapılış s1rasını etkilediğinden, Yİ istasyonun atanabilecek görevlerin sayısı Yİ istasyonunun bulunduğu pozisyona bağlı olarak değişebilmekte ve bu durumda çevrim süresini etkileme potansiyeli bulundurmaktadır. Bu nedenle Yİ istasyonunun bulunduğu pozisyon değiştirilerek, en uygun pozisyonda olmasını sağlamak çevrim süresini minimize etmek açısından önem kazanabilir. Çalışmada Yİ istasyonunun son üç istasyona ait pozisyonlarda bulunduğu durumlar dikkate alınmıştır. Bu doğrultuda Yİ istasyonunun bulunduğu pozisyona göre üç farklı alternatif tasarım oluşturulmaktadır. Yİ istasyonunun son istasyon (Şekil 3) ve sondan önceki istasyon (Şekil 4) pozisyonlarında bulunduğu durum için oluşturulan tasarımlar verilmektedir. 


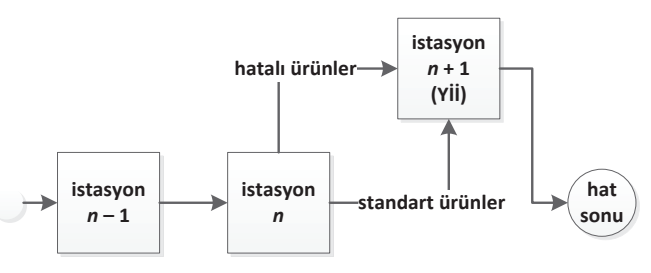

Şekil 3. Yİ İstasyonunun (YIİ) son istasyon pozisyonunda bulunmas1

Şekil 3'de Yİ istasyonu $(n+1)$. istasyon pozisyonundadır. Burada Yİ istasyonu sadece kalite kontrol sonucunda çıkan hatalı ürünlerin düzenlendiği bir istasyon olarak değil, aynı zamanda $n$. istasyondan gelen iş parçasını işleyen bir istasyon $((n+1)$. istasyon) olarak da görev yapmaktadır. Şekil 4'te Yİ istasyonu $n$. istasyon pozisyonundadır, son istasyondan gelen hatalı ürünlere ek olarak, bir önceki istasyondan $((n-1)$. istasyon) gelen iş parçasının da işlendiği standart bir istasyon olarak da görev yapmaktadır. Benzer şekilde, Yİ istasyonu $(n-1)$. istasyon pozisyonunda olduğunda, diğer durumlarda olduğu gibi son istasyondan (( $n+1)$. istasyon) gelen hatalı ürünlere ek olarak, bir önceki istasyondan $((n-2)$. istasyon) gelen iş parçasının da işlendiği standart bir istasyon olarak da görev yapmaktadır.

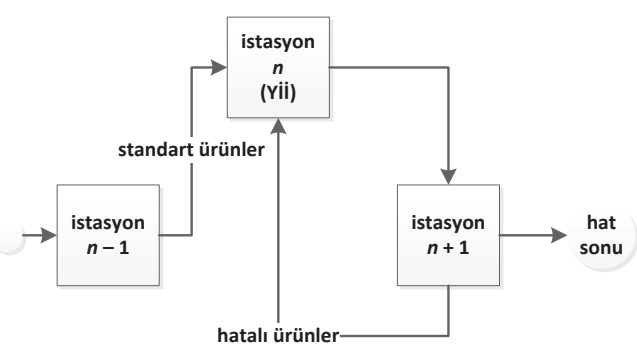

Şekil 4. Yİ İstasyonunun (Yïi) son istasyon öncesi pozisyonda bulunmas1

Yİ istasyonunun daha önceki istasyonların bulunduğu pozisyonlara alınması da mümkün olabilir. Bununla birlikte Yİ istasyonunun öncelikli görevinin hatalı ürünlerin yeniden işlenmesi olduğu düşünüldüğünde, bu istasyonun son istasyon pozisyonundan fiziksel olarak uzaklaşması, yeniden işleme gerektiren parçaların taşıma mesafelerinin ve sürelerinin artmasına neden olmaktadır. Öte yandan, Yİ istasyonu son istasyon pozisyonunda yer alması yerine, verilen alternatif tasarımlarda olduğu gibi son istasyon yakınlarındaki pozisyonlarda bulunması durumunda, öncelik ilişkileri kısıtlarına bağlı olarak Yİ istasyonuna atanabilecek potansiyel görevlerin sayısı değişebilmektedir. Bununla birlikte,
Yİ istasyon pozisyonu ilk istasyona doğru yaklaştığında, yeniden işleme gerektiren ürünlerin taşıma süre ve mesafeleri artarken, Yİ istasyon pozisyonu son istasyona doğru yaklaştığında ise yeniden işleme gerektiren ürünlerin taşıma süre ve mesafelerinin azalması söz konusudur. Dolayısıyla, Yİ istasyonunun optimal pozisyonu bütün bu unsurların (taşıma süre ve mesafeleri, öncelik ilişkileri kısıtlarına bağlı olarak Yİ istasyonuna atanabilecek görevlerin sayısı) birlikte dikkate alınmasıyla belirlenebilir.

$\mathrm{Bu}$ çalışmada, Yİ istasyonunun standart bir iş istasyonu olarak kullanılması durumunda çevrim süresini minimize etmek için bir karışık-tamsayılı programlama modeli önerilmektedir. Model detayları aşağıda verilmektedir.

İndisler, Parametreler ve Değişkenler;

i Görevler

$j \quad$ iş istasyonları

$m$ görev sayıs1

$n \quad$ standart iş istasyonu sayısı

$r \quad$ Yİ istasyonu pozisyonu

$\beta$ hata oranı katsayıs

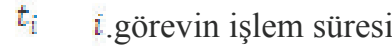

$\gamma$ Yİ istasyonuna atanabilecek işlerin sayısını sınırlandırmak için kullanılan ceza katsayısı

$i$ görevi $k$ görevinin öncülü ise 1 , değilse 0 değerini

$p_{i k} \quad$ alan öncelik ilişkisi matrisi elemanları

c çevrim süresi değişkeni

$x_{i j} \quad i$ görevi $j$ istasyonuna atanmışsa 1 , diğer durumlarda

$x_{i j} \quad 0$ değerini alan karar değişkenleri

Amaç Fonksiyonu;

$\min z=c$

Kisitlar;

$$
\begin{aligned}
& \sum_{j=1}^{n+1} x_{i j}=1, \quad \forall i \\
& \sum_{j=1}^{n+1} j x_{i j} \leq \sum_{j=1}^{n+1} j x_{k j}, \quad \forall i, k: p_{i k}=1 \\
& \sum_{i=1}^{m} t_{i} x_{i j} \leq c, \quad \forall j \\
& \beta^{\gamma}\left(\sum_{i=1}^{m} t_{i} x_{i j}\right) \leq c, \quad j=r \\
& x_{i j} \in\{0,1\}, \quad \forall i, j \\
& c \geq 0
\end{aligned}
$$


Modelin amaç fonksiyonu (Denklem 1) çevrim süresini minimize etmektedir. Denklem 2 ile verilen kısıt görevlerin istasyonlara atanmasını, Denklem 3 ile verilen kısıt da görevler arasındaki öncelik ilişkilerini dikkate alınmasını sağlamaktadır. Denklem 4 bir istasyona atanan görevlerin işlem sürelerinin toplamını çevrim süresi ile sınırlandırırken, Denklem 5 ile montaj hattındaki hata oranına bağlı olarak Yİ istasyonuna atanabilecek olan görevler sınırlandırılmaktadır. Denklemde bulunan $\beta$ hata oranı katsayısı ile Yİ istasyonuna atanan görevlerin toplam işlem süresinin belirli bir oranının hata giderme işlemleri için kullanılmasıyla, Yİ istasyonuna atanan görevlerin işlem sürelerinin toplamının çevrim süresini aşmaması sağlanmaktadır. $\mathrm{Bu}$ denklemde bulunan $\gamma$ parametresi Yİ istasyonuna atanabilecek işlerin sayısını sınırlandırmak için kullanılan bir ceza katsayısı olarak tanımlanmış olup, bu şekilde Yİ istasyonunda çalışan kişilerin maruz kalabileceği ergonomik risk unsurlarının (YI istasyonunda standart olmayan işlerin yapılması nedeniyle daha fazla yorulma vb.) da modele dâhil edilmesi amaçlanmaktadır. Denklem 6 ve 7 değişken tanımlarını ifade etmektedir.

\section{BULGULAR}

Bu çalışmada Jackson, Mitchells ve Heskiaoff test problemleri kullanılmıştır. Söz konusu test problemlerine http:// assembly-line-balancing.mansci.de adresinden erişilebilir. Önerilen yöntemin çalışması detaylı olarak 11 görevden oluşan Jackson test problemi üzerinde gösterilmiştir. Jackson örneklemi için işlem süreleri ve görevlerin öncelik ilişkilerini gösteren bir ağ yapısı (öncelik ilişkisi diyagramı) Şekil 5'te verilmiştir. Bu ağ yapısında düğümler görevleri, bağlantılar da görevler arasındaki öncelik ilişkilerini göstermektedir.

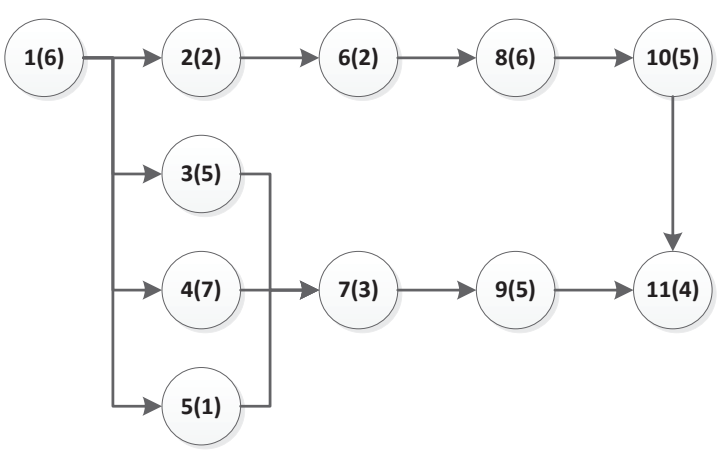

Şekil 5. Jackson örneklemi için öncelik ilişkisi diyagramı ve işlem süreleri

Önerilen modelde Yİ istasyonu hatalı ürünlerin yeniden işlendiği bir istasyon olarak kullanılmasının yanısıra standart bir iş istasyonu olarak kullanılmaktadır. $\mathrm{Bu}$ nedenle, Yİ istasyonunun ne oranda hatalı ürünler için kullanıldığı çevrim süresini etkileyen bir faktördür. Montaj hattındaki hata oranının düşük seviyede olması durumunda Yİ istasyonunun kullanım oranı düşük olacağından, bu istasyona atanabilecek görevlerin sayısı (diğer istasyonlarda yapılabilecek olan diğer görevler) artmaktadır. Bu nedenle, bu istasyona daha fazla görev ataması gerçekleştirilebilir. Ancak hata oranı yüksek olduğunda ise Yİ istasyonu çoğunlukla hatalı ürünlerin işlenmesi için kullanılacağından, YI istasyonuna daha az sayıda görev ataması yapılabilir. Hata oranının çözüme olan etkisini gösterebilmek için model $\% 0$ $(\beta=1,00), \% 25(\beta=1,25), \% 50(\beta=1,50)$ olmak üzere üç farklı hata oranı için çözülmüştür. Jackson örneklemi ve diğer test problemlerinin çözümleri Intel (R) Core ${ }^{\mathrm{TM}}$ i7$7500 \mathrm{CPU}$ 2.70GHz 2.90GHz donanım özellikleri olan kişisel bir bilgisayarda, Mathematical Programming Language (MPL) ortamında GUROBI çözücüsü kullanılarak gerçekleştirilmiştir.

Montaj hattındaki hata oranına ek olarak, Yİ istasyonunun pozisyon değişiminin çözüme olan etkileri incelenmiştir. Yaklaşımın gösterimi için kullanılan Jackson örneklemi, montaj hattında 3 istasyon olan durum göz önüne alınarak çözülmüştür. Görevler arasındaki öncelik ilişkileri, görevlerin yapıllış sırasını etkilediğinden, Yİ istasyonu pozisyonuna göre çevrim süresi değişebilmektedir. Bu nedenle, Yİ istasyonunun pozisyonunun değiştirilmesinin çözüm üzerindeki etkisini göstermek amacı ile farklı Yİ istasyonu pozisyonları dikkate alınmıştır. Buna ek olarak Jackson örneklemi, Yİ istasyonuna atanabilecek olan görevlerin sayısını sınırlandırmak için kullanılan $\gamma$ ceza katsayısı $\gamma=1$ ve $\gamma=2$ olarak alınarak iki farklı $\gamma$ değerinin etkileri incelenmiştir.

Yİ istasyonu pozisyonu son 3 istasyona karşıllk gelecek şekilde değiştirilerek çözümler elde edilmiştir. Bu nedenle, örneklemin 3 istasyon içeren versiyonu dikkate alındığından (Yİ istasyonu ile birlikte toplam olarak 4 istasyon), Yİ istasyonunun, 2,3 ve 4 . istasyon pozisyonlarında olmak üzere üç farklı durumu için model çözülmüştür. Hata oranın $\% 25$ $(\beta=1.25)$ ve $\gamma=1$ olan durum üç farklı Yİ istasyonu pozisyon için elde edilen sonuçlar Şekil 6-a, Şekil 6-b ve Şekil 6-c'de gösterilmiştir.

Şekil 6-a'da Yİ istasyonunun 4. istasyon pozisyonunda (son istasyon) olduğu durumdaki çözümü göstermektedir. Yİ istasyonunun sondan bir önceki istasyon (3. istasyon) pozisyonunda olması durumunda elde edilen çözüm ise Şekil 6-b'de görülmektedir. Benzer şekilde, Şekil 6-c'de Yİ istasyonunun 2. istasyon pozisyonunda olduğu durum verilmiştir. Yİ istasyonu 2. istasyon pozisyonunda olduğunda (Şekil 6-c) çevrim süresinin 12,5 zaman birimi olduğu ve bu 
istasyona, üç görevin atandığı görülmektedir. Yİ istasyonu 3. istasyon pozisyonunda olduğu durumda (Şekil 6-b), Yİ istasyonuna sadece bir görev atandığı ve çevrim süresinin ise 13 zaman birimi olduğu görülmektedir. Yİ istasyonunun son istasyon olması durumunda (Şekil 6-a) ise çevrim süresinin yine 13 zaman birimi olduğu, bununla birlikte bu istasyona iki görev atandığı görülmektedir.

Şekil 7-a, Şekil 7-b ve Şekil 7-c de hata oranı \%25 ( $\beta=1.25$ ) ve $\gamma=2$ olan durum dikkate alınarak üç farklı Yİ istasyonu pozisyonu için elde edilen sonuçlar verilmiştir. Şekil 7-a'da Yİ istasyonunun 4. istasyon pozisyonunda (son istasyon) olduğu durum, Şekil 7-b'de Yİ istasyonunun 3. istasyon pozisyonunda olduğu durum ve Şekil 7-c'de Yİ istasyonunun 2. istasyon pozisyonunda olduğu durum için elde edilen sonuçlar verilmiştir. Yİ istasyonu 2. istasyon pozisyonunda olduğunda çevrim süresinin 13 zaman birimi olduğu ve Yİ istasyonuna sadece bir görev atandığ görülmektedir. Yİ istasyonu 3. istasyon pozisyonunda olduğu durumda çevrim süresinin $\gamma=1$ olan durumdaki çevrim süresiyle eşit olduğu ancak Yİ istasyonuna atanan görevlerin sayısında arttığı görülmektedir. Yİ istasyonu 4. istasyon pozisyonunda olduğu durumda çevrim süresinin 14,04 zaman birimi olduğu ve $\gamma=1$ olan durum ile kıyaslandığında ise çevrim süresinin arttığı görülmektedir.

Bu sonuçlardan da görüldüğü gibi, Yİ istasyonunun bulunduğu pozisyona göre çevrim süresi ve istasyonlara atanan görevlerde değişiklikler olabilmektedir. Buna ek olarak Yİ istasyonuna atanan görevlerin sayısı öncelik ilişkilerine ve $\gamma$ değerine bağlı olarak da değişkenlik gösterebilmektedir.

Farklı Yİ istasyonu pozisyonlarına ek olarak, üç farklı hata oranı ve iki farklı $\gamma$ değeri için elde edilen sonuçlar Tablo 1 ( $\gamma=1$ olan durum) ile Tablo 2 'de ( $\gamma=2$ olan durum) verilmektedir.

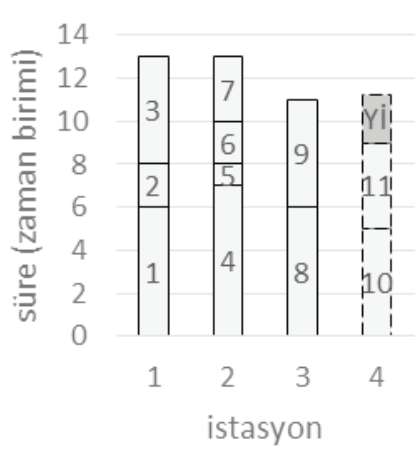

$a$.

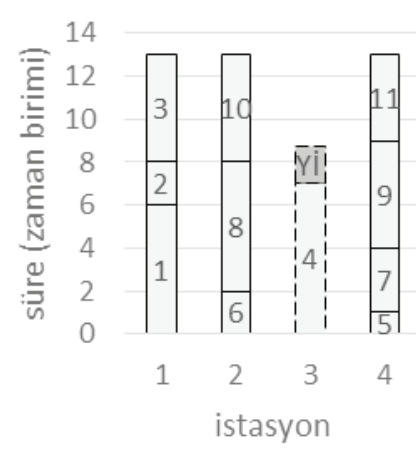

$b$.

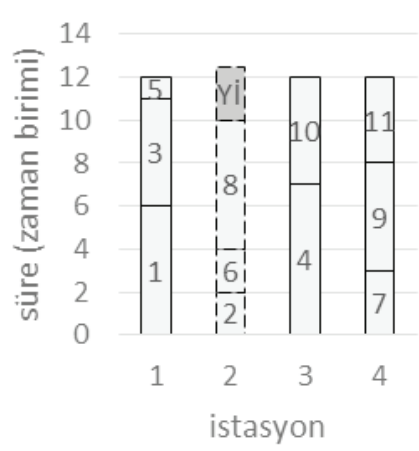

c.

Şekil 6. Hata oranının \%25 olduğu durumda ve $\gamma=1$ için Yİ istasyonunun (a) 4. istasyon, (b) 3. istasyon ve (c) 2. istasyon pozisyonunda olduğu durumdaki görev atamaları

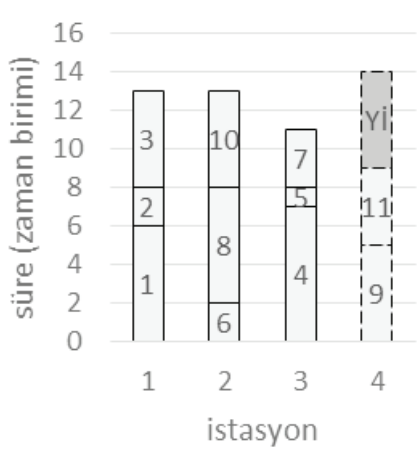

$a$.

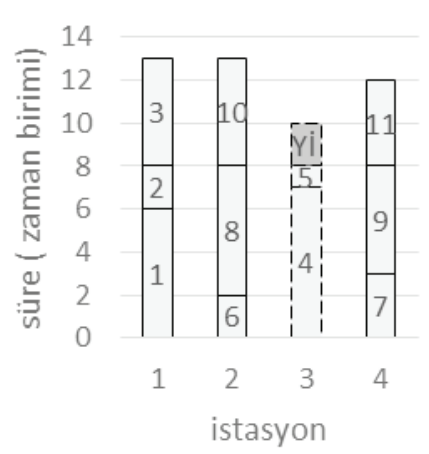

$b$.

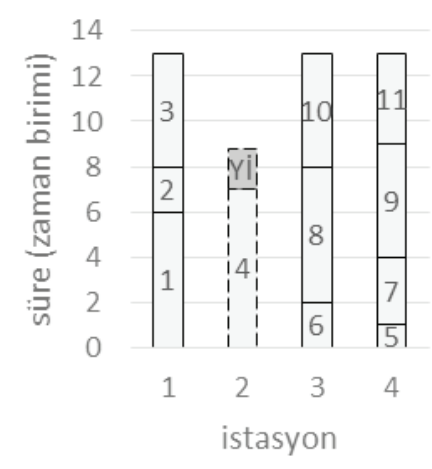

$c$.

Şekil 7. Hata oranının \%25 olduğu durumda ve $\gamma=2$ için Yİ istasyonunun (a) 4. istasyon, (b) 3. istasyon ve (c) 2. istasyon pozisyonunda olduğu durumdaki görev atamaları 
Tablo 1. Jackson örneklemi 3 istasyonlu versiyon için çözüm sonuçları $(\gamma=1)$

\begin{tabular}{|c|c|c|c|c|c|c|c|c|c|c|c|c|c|}
\hline \multirow{2}{*}{ İS } & \multirow{2}{*}{ ÇS } & \multirow{2}{*}{$\begin{array}{l}\mathrm{HE} \\
(\%)\end{array}$} & \multirow{2}{*}{$\begin{array}{l}\text { BÇS } \\
\text { (sn) }\end{array}$} & \multirow{2}{*}{\begin{tabular}{|l|} 
Yİ \\
İstasyonu \\
Pozisyonu \\
\end{tabular}} & \multicolumn{3}{|c|}{$\beta=1,00$} & \multicolumn{3}{|c|}{$\beta=1,25$} & \multicolumn{3}{|c|}{$\beta=1,50$} \\
\hline & & & & & BÇS (sn) & ÇS & HE (\%) & BÇS (sn) & ÇS & HE (\%) & BÇS (sn) & ÇS & HE (\%) \\
\hline \multirow{3}{*}{3} & \multirow{3}{*}{16,00} & \multirow{3}{*}{72,00} & \multirow{3}{*}{$\approx 0,00$} & 2 & 0,14 & 12,00 & 95,83 & 0,01 & 12,50 & 92,00 & 0,01 & 13,00 & 88,46 \\
\hline & & & & 3 & 0,01 & 12,00 & 95,83 & 0,01 & 13,00 & 88,46 & 0,01 & 13,00 & 88,46 \\
\hline & & & & 4 & 0,01 & 12,00 & 95,83 & 0,09 & 13,00 & 88,46 & $\approx 0,00$ & 13,00 & 88,46 \\
\hline
\end{tabular}

İS (İstasyon Sayısı), ÇS (Çevrim Süresi), HE (Hat Etkinliği), BÇS (Bilgisayar Çözüm Süresi)

Tablo 2. Jackson örneklemi 3 istasyonlu versiyon için çözüm sonuçları $(\gamma=2)$

\begin{tabular}{|c|c|c|c|c|c|c|c|c|c|c|c|c|c|}
\hline \multirow{2}{*}{ İS } & \multirow{2}{*}{ ÇS } & \multirow{2}{*}{ HE (\%) } & \multirow{2}{*}{$\begin{array}{l}\text { BÇS } \\
\text { (sn) }\end{array}$} & \multirow{2}{*}{$\begin{array}{l}\text { Yİ } \\
\text { İstasyonu } \\
\text { Pozisyonu }\end{array}$} & \multicolumn{3}{|c|}{$\beta=1,00$} & \multicolumn{3}{|c|}{$\beta=1,25$} & \multicolumn{3}{|c|}{$\beta=1,50$} \\
\hline & & & & & BÇS (sn) & ÇS & HE (\%) & BÇS (sn) & ÇS & HE (\%) & BÇS (sn) & ÇS & HE (\%) \\
\hline \multirow{3}{*}{3} & \multirow{3}{*}{16,00} & \multirow{3}{*}{72,00} & \multirow{3}{*}{$\approx 0,00$} & 2 & 0,14 & 12,00 & 95,83 & 0,01 & 13,00 & 88,46 & 0,01 & 14,00 & 82,14 \\
\hline & & & & 3 & 0,01 & 12,00 & 95,83 & 0,01 & 13,00 & 88,46 & 0,01 & 14,00 & 82,14 \\
\hline & & & & 4 & 0,01 & 12,00 & 95,83 & 0,01 & 14,04 & 81,90 & 0,01 & 15,00 & 76,66 \\
\hline
\end{tabular}

İS (İstasyon Sayısı), ÇS (Çevrim Süresi), HE (Hat Etkinliği), BÇS (Bilgisayar Çözüm Süresi)

Tablo 1'deki sonuçlar analiz edildiğinde, farklı hata oranları için Yİ istasyonunun pozisyonuna göre çevrim sürelerinde değişiklikler olabildiği görülmektedir. 3 istasyonlu Jackson örneklemi için hata oranının etkileri incelendiğinde, hata oranı artışına bağlı olarak, Yİ istasyonu hatalı ürünler için daha fazla kullanılması nedeniyle, çevrim süresinin de $\operatorname{arttığı;~çevrim~süresinin~artması~hat~etkinliğini~olumsuz~}$ yönde etkilediği için de hat etkinliğinin azaldığı görülmektedir. Buna ek olarak, Yİ istasyonunun standart bir istasyon olarak kullanılması durumunda hat etkinliğinin artması söz konusudur. Yİ istasyonu standart bir istasyon olarak kullanılmadığ 2. istasyon pozisyonunda standart bir istasyon olarak kullanıldığı durumda (\%0 hata oranı için) hat etkinliğinin $\% 95,83$ olduğu görülmektedir. Benzer şekilde Tablo 2'de verilen sonuçlar incelendiğinde ise $\gamma$ değeri arttığında çevrim süresinin arttığı ve daha öncede bahsedildiği gibi hat etkinliğinin olumsuz yönde etkilendiği yani azaldığı görülmektedir.

Tablo 3. Farklı test örneklemleri için deneysel sonuçlar $(\gamma=1)$

\begin{tabular}{|c|c|c|c|c|c|c|c|c|c|c|}
\hline \multirow[b]{2}{*}{ Problem } & \multirow[b]{2}{*}{ İS } & \multirow[b]{2}{*}{ ÇS } & \multirow[b]{2}{*}{$\begin{array}{c}\text { BÇS } \\
\text { (sn) }\end{array}$} & \multirow{2}{*}{$\begin{array}{l}\text { Yİ } \\
\text { İstasyonu } \\
\text { Pozisyonu }\end{array}$} & \multicolumn{2}{|c|}{$\beta=1,00$} & \multicolumn{2}{|c|}{$\beta=1,25$} & \multicolumn{2}{|c|}{$\beta=1,50$} \\
\hline & & & & & ÇS & $\begin{array}{l}\text { BÇS } \\
\text { (sn) }\end{array}$ & ÇS & $\begin{array}{c}\text { BÇS } \\
\text { (sn) }\end{array}$ & ÇS & $\begin{array}{l}\text { BÇS } \\
\text { (sn) }\end{array}$ \\
\hline \multirow{6}{*}{ Jackson (11 görev) } & \multirow{3}{*}{3} & \multirow{3}{*}{16,00} & \multirow{3}{*}{$\approx 0,00$} & 2 & 12,00 & 0,14 & 12,50 & 0,01 & 13,00 & 0,01 \\
\hline & & & & 3 & 12,00 & 0,01 & 13,00 & 0,01 & 13,00 & 0,01 \\
\hline & & & & 4 & 12,00 & 0,01 & 13,00 & 0,09 & 13,50 & $\approx 0,00$ \\
\hline & \multirow{3}{*}{4} & \multirow{3}{*}{12,00} & \multirow{3}{*}{$\approx 0,00$} & 3 & 10,00 & 0,13 & 11,00 & 0,07 & 11,00 & 0,01 \\
\hline & & & & 4 & 10,00 & 0,01 & 11,00 & 0,01 & 11,00 & 0,01 \\
\hline & & & & 5 & 10,00 & 0,01 & 11,00 & 0,01 & 11,00 & 0,01 \\
\hline \multirow{6}{*}{ Mitchells (21 görev) } & \multirow{3}{*}{3} & \multirow{3}{*}{35,00} & \multirow{3}{*}{0,01} & 2 & 27,00 & 0,14 & 28,00 & 0,06 & 30,00 & 0,01 \\
\hline & & & & 3 & 27,00 & 0,01 & 28,00 & 0,01 & 30,00 & 0,07 \\
\hline & & & & 4 & 27,00 & 0,01 & 28,00 & 0,01 & 30,00 & 0,01 \\
\hline & \multirow{3}{*}{5} & \multirow{3}{*}{21,00} & \multirow{3}{*}{0,01} & 4 & 18,00 & 0,02 & 19,00 & 0,05 & 19,00 & 0,35 \\
\hline & & & & 5 & 18,00 & 0,02 & 19,00 & 0,10 & 19,00 & 0,04 \\
\hline & & & & 6 & 18,00 & 0,02 & 19,00 & 0,03 & 19,50 & 0,07 \\
\hline \multirow{6}{*}{ Heskiaoff (28 görev) } & \multirow{3}{*}{4} & \multirow{3}{*}{256,00} & \multirow{3}{*}{0,04} & 3 & 205,00 & 0,29 & 214,00 & 0,26 & 220,00 & 0,03 \\
\hline & & & & 4 & 205,00 & 0,05 & 214,00 & 0,32 & 220,00 & 0,04 \\
\hline & & & & 5 & 205,00 & 0,05 & 214,00 & 0,47 & 220,00 & 0,03 \\
\hline & \multirow{3}{*}{5} & \multirow{3}{*}{205,00} & \multirow{3}{*}{0,04} & 4 & 171,00 & 0,06 & 177,00 & 0,05 & 181,00 & 0,22 \\
\hline & & & & 5 & 171,00 & 0,04 & 177,00 & 0,06 & 181,00 & 0,03 \\
\hline & & & & 6 & 171,00 & 0,13 & 177,00 & 0,04 & 181,00 & 0,07 \\
\hline
\end{tabular}

İS (İstasyon Sayısı), ÇS (Çevrim Süresi), HE (Hat Etkinliği), BÇS (Bilgisayar Çözüm Süresi) 
Örneğin; hata oranı $\% 50(\beta=1,50)$ ve $\gamma=1$ olan durumda, Yİ istasyonu 2. istasyon pozisyonunda olduğunda çevrim süresi 13 iken; $\gamma=2$ olan durumda ise çevrim süresinin 14 zaman birimi olduğu ve arttığı görülmektedir.

Jackson test problemindeki sonuçlara ek olarak, farklı MHDP test örneklemleri (Mitchells ve Heskiaoff) kullan1larak modelin performansı analiz edilmiştir. Tablo 3'de her örneklem için Uğurdağ ve ark. [32] tarafından yapılan çalışmada verilen iki farklı istasyon sayısı kombinasyonu dikkate alınarak, Yİ istasyonunun üç farklı pozisyonda bulunması durumu üç farklı hata oranı ve $\gamma=1$ için çevrim süreleri ve modele ilişkin çözüm süreleri verilmiştir.

Tablo 3'te görüldüğü gibi Yİ istasyonunun hatalı ürünlerin yeniden işlendiği bir istasyon olarak kullanılmasına ek olarak, diğer görevlerin atandığı standart bir iş istasyonu olarak kullanılması ile çevrim sürelerinde önemli iyileşmeler sağlayabilmektedir. Modelin çözüm süreleri Yİ istasyonunun farklı pozisyonlarına ve farklı hata oranlarına bağlı olarak, 0,29 saniye (Heskiaoff örneklemi-4 istasyonlu versiyon, Yİ istasyonunun 3. pozisyonda olduğu durum ve $\% 0$ hata oranı için) ile $\approx 0$ saniye (Jackson örneklemi-3 istasyonlu versiyon, Yİ istasyonunun 4. pozisyonda olduğu durum ve $\% 50$ hata oranı için) arasında değişkenlik göstermektedir. Öte yandan, çevrim süresinin değişimi incelendiğinde, dikkate alınan en büyük örneklem için (Heskiaoff örneklemi) standart modelden elde edilen çevrim sürelerinin önemli oranda azaldığı görülmektedir. Örneğin, 5 istasyonlu versiyonda 205 zaman birimi olan çevrim süresinin; hata oranının $\% 0(\beta=1,00)$ olduğu durumda 171 zaman birimine, hata oranının $\% 25(\beta=1,25)$ olduğu durumda 177 zaman birimine, hata oranının $\% 50(\beta=1,50)$ olduğu durumda 181 zaman birimine düştüğü görülmektedir. Buna ek olarak, Yİ istasyonunun pozisyonunun da çevrim süresi üzerinde daha küçük miktarlarda da olsa etkileri olabildiği durumlar söz konusudur.

\section{TARTIŞMA VE SONUÇ}

$\mathrm{Bu}$ çalışmada, montaj hatlarında hatalı ürünlerin yeniden işlendiği bir istasyon olarak kullanılan Yİ istasyonunun standart bir iş istasyonu olarak kullanılması dikkate alınarak, bir karışık-tamsayılı programlama modeli önerilmiştir. Önerilen model literatürdeki çeşitli örneklemler üzerinde test edilmiştir. Çalışma kapsamında, sadece Yİ istasyonuna standart bir iş istasyonu olarak görevlerin atanmasının sağlanmasina ek olarak, Yİ istasyonunun farklı pozisyonlarda bulunması (son istasyon ve daha önceki istasyon pozisyonlarında) ve montaj hattındaki hata oranlarının da çözüme olan etkileri analiz edilmiştir.
Yİ istasyonu son istasyondan çıkan hatalı ürünlerin yeniden işlendiği bir istasyon olarak kullanıldığından Yİ istasyonu pozisyonu hattın başına doğru yaklaştığında hatalı ürünlerin taşıma süreleri/mesafeleri artacaktır. Bu nedenle, önerilen yaklaşım, montaj hattında üretilen ürünlerin taşınmasının ergonomik açıdan zorluk içermeyen sistemlerde daha yüksek uygulama potansiyeline sahip olabilir. Buna ek olarak, Yİ istasyonunda bütün görevlerin gerçekleştirilebiliyor olması varsayımı nedeniyle de önerilen yaklaşımın yüksek esneklik içeren sistemler (bütün görevlerin gerçekleştirilmesine olanak sağlayacak şekilde istasyonların düzenlenebildiği sistemler) için daha uygun olduğu söylenebilir.

Yİ istasyonunun standart bir iş istasyonu olarak kullanılması ile özellikle montaj hattındaki hata oranının düşük olduğu durumlarda çevrim süresinde iyileşme sağlanabileceği görülmektedir. Gerçek hayattaki montaj hatlarında Yİ istasyonunun standart bir iş istasyonu olarak kullanılabilmesi için gerekli düzenlemelerin yapılması durumunda, bu istasyonda bulunan kaynakların daha etkin bir şekilde kullanılması ve montaj hattı çevrim süresinin azaltılması mümkün olabilir. Buna ek olarak, Yİ istasyonunun farklı pozisyonlarda konumlandırılmasının da çözümü etkilediği görülmektedir. Yİ istasyonunun pozisyonu belirlenirken, montaj hattındaki önşart ilişkileri ve ergonomik unsurlar birlikte değerlendirilebilir.

Önerilen model, daha büyük boyutlu gerçek-hayat problemlerinin çözümünde daha uzun çözüm süreleri gerektirebileceğinden, daha büyük boyutlu problemlerin çözümü için sezgisel ve meta-sezgisel yöntemler geliştirilmesi gelecek çalışmalar kapsamında dikkate alınabilir. Gelecek çalışmalarda, Yİ istasyonunun farklı pozisyonlarda kullanılması ile ilgili olarak oluşması söz konusu olabilecek maliyetlerin (hatalı ürünleri taşınması vb.) de dikkate alındığı daha geniş kapsamlı analizler de yapılabilir.

\section{KAYNAKLAR}

[1] Hossain, M. S. J. ve Sarker, B. R. (2016). Optimal locations of on-line and off-line rework stations in a serial production system. Int. J. Prod. Res., 54(12), 3603-3621.

[2] Bryton, B. (1954). Balancing of a continuous production line. Yüksek Lisans Tezi, Northwestern University, Evanston.

[3] Salveson, M. E. (1955). The assembly line balancing problem. The Journal of Industrial Engineering, 6(3), 18-25.

[4] Ghosh, S. ve Gagnon, R. J. (1989). A comprehensive literature review and analysis of the design, balancing and scheduling of assembly systems. Int. J. Prod. Res., 27(4), 637-670. 
[5] Baybars, I. (1986). A survey of exact algorithms for the simple assembly line balancing problem. Manage. Sci., 32(8), 909932.

[6] Becker, C. ve Scholl A. (2006). A survey on problems and methods in generalized assembly line balancing. Eur. J. Oper. Res., 168(3), 694-715.

[7] Scholl, A. ve Becker, C. (2006). State-of-the-art exact and heuristic solution procedures for simple assembly line balancing. Eur. J. Oper. Res., 168(3), 666-693.

[8] Kilincci, O. (2010). Petri net-based heuristic for simple assembly line balancing problem of Type 2. The International Journal of Advanced Manufacturing Technology, 46(1), 329338.

[9] Wei, N. ve Chao, I. (2011). A solution procedure for Type E simple assembly line balancing problem. Comput. Ind. Eng., 61(3), 824-830.

[10] Sivasankaran, P. ve Shahabudeen, P. (2014). Literature review of assembly line balancing problems. The International Journal of Advanced Manufacturing Technology, 73:665-1694.

[11] Kara, Y., Özgüven, C., Yalçın, N. ve Atasagun, Y. (2011). Balancing straight and U-shaped assembly lines with resource dependent task times. Int. J. Prod. Res., 49(21), 6387-6405.

[12] Gökçen, H., Ağpak, K. ve Benzer R. (2006). Balancing of parallel assembly lines. Int. J. Prod. Econ., 103(2), 600-609.

[13] Özcan, U. ve Toklu, B. (2010). Balancing two-sided assembly lines with sequence-dependent setup times, Int. J. Prod. Res., 48(18), 5363-5383.

[14] Ağpak, K. ve Zolfaghari, S. (2015). Mathematical models for parallel two-sided assembly line balancing problems and extensions, Int. J. Prod. Res., 53(4), 1242-1254.

[15] Amen, M. (2006). Cost-oriented assembly line balancing: model formulations, solution difficulty, upper and lower bounds. Eur. J. Oper. Res., 168(3), 747-770.

[16] Erel, E. ve Gokcen, H. (1999). Shortest-route formulation of mixed-model assembly line balancing problem. Eur. J. Oper. Res., 116(1), 194-204.

[17] Gokcen, H. ve Erel, E. (1997). A goal programming approach to mixed-model assembly line balancing problem. Int. J. Prod. Econ., 48(2), 177-185.

[18] Battaia, O. ve Dolgui, A. (2013). A taxonomy of line balancing problems and their solution approaches. Int. J. Prod. Econ., 142(2), 259-277.

[19] Boysen, N., Fliedner, M. ve Scholl, A. (2007). A classification of assembly line balancing problems. Eur. J. Oper. Res., 183(2), 674-693.
[20] Deckro, R. F. ve Rangachari, S. (1990). A goal approach to assembly line balancing. Computers \& operations research, 17(5), 509-521.

[21] Kilincci, O. ve Bayhan, G. M. (2006). A Petri net approach for simple assembly line balancing problems. The International Journal of Advanced Manufacturing Technology, 30(11), 1165-1173.

[22] Rubinovitz, J. ve Levitin, G. (1995). Genetic algorithm for assembly line balancing. Int. J. Prod. Econ., 41(1), 343-354.

[23] Kim, Y. K., Kim, Y. J. ve Kim, Y. (1996). Genetic algorithms for assembly line balancing with various objectives. Comput. Ind. Eng., 30(3), 397-409.

[24] Suwannarongsri, S. ve Puangdownreong, D. (2008). Optimal assembly line balancing using tabu search with partial random permutation technique. International Journal of Management Science and Engineering Management, 3(1), 3-18.

[25] Tapkan, P., Ozbakir, L. ve Baykasoglu, A. (2012) Modeling and solving constrained two-sided assembly line balancing problem via bee algorithms. Appl. Soft Comput., 12(11), 3343-3355.

[26] Baykasoglu, A. ve Dereli, T. (2008). Two-sided assembly line balancing using an ant-colony-based heuristic. The International Journal of Advanced Manufacturing Technology. 36(56), 582-588.

[27] Baykasoğlu, A. (2006). Multi-rule multi-objective simulated annealing algorithm for straight and $U$ type assembly line balancing problems. Journal of Intelligent Manufacturing. 17(2), 217-232.

[28] Mutlu, Ö. ve Özgörmüş, E. (2012). A fuzzy assembly line balancing problem with physical workload constraints. Int. J. Prod. Res., 50(18), 5281-5291.

[29] Baykasoğlu, A. ve Akyol, Ş.D. (2014). Ergonomik montaj hattı dengeleme. Gazi Üniversitesi Mühendislik-Mimarlık Fakültesi Dergisi, 29(4), 785-792.

[30] Güner, B. ve Hasgül, S. (2012). Sürdürülebilir denge için ergonomik faktörleri içeren U-tipi montaj hattı dengelemesi. Gazi Üniversitesi Mühendislik-Mimarlık Fakültesi Dergisi, 27(2), 407-415.

[31] Barathwaj, N., Raja, P. ve Gokulraj, S. (2015). Optimization of assembly line balancing using genetic algorithm. Journal of Central South University, 22(10), 3957-3969.

[32] Uğurdağ, H. F., Rachamadugu, R. ve Papachristou, C. A. (1997). Designing paced assembly lines with fixed number of stations. Eur. J. Oper. Res., 102(3), 488-501. 